\title{
Fluoride and aluminum release from restorative materials using ion chromatography
}

\author{
Zeynep OKTE1', Sule BAYRAK², Ulvi Reha FIDANCI ${ }^{3}$, Tevhide SEL ${ }^{3}$
}

1- DDS, PhD, Professor, Department of Pediatric Dentistry, Faculty of Dentistry, Ankara University, Ankara, Turkey.
2- DDS, PhD, Assistant Professor, Department of Pediatric Dentistry, Faculty of Dentistry, Ondokuz Mayis University, Samsun, Turkey.
3- DVM, PhD, Professor, Department of Biochemistry, Faculty of Veterinary Sciences, Ankara University, Ankara, Turkey.

Corresponding address: Sule Bayrak - Department of Pediatric Dentistry, Faculty of Dentistry - University of Ondokuz Mayis - 55139 - Kurupelit - Samsun - TURKEY - Phone: +90 362 3121919/3365 - Fax: +903624576032 - e-mail: suleb76@yahoo.com

Received: October 13, 2009 - Accepted: May 2, 2010

\section{ABSTRACT}

\begin{abstract}
bjective: The aim of this study was to determine the amounts of fluoride and aluminum released from different restorative materials stored in artificial saliva and double-distilled water. Material and Methods: Cylindrical specimens $(10 \times 1 \mathrm{~mm})$ were prepared from 4 different restorative materials (Kavitan Plus, Vitremer, Dyract Extra, and Surefil). For each material, 20 specimens were prepared, 10 of which were stored in $5 \mathrm{~mL}$ artificial saliva and 10 of which were stored in $5 \mathrm{~mL}$ of double-distilled water. Concentrations of fluoride and aluminum in the solutions were measured using ion chromatography. Measurements were taken daily for one week and then weekly for two additional weeks. Data were analyzed using two-way ANOVA and Duncan's multiple range tests $(p<0.05)$. Results: The highest amounts of both fluoride and aluminum were released by the resin-modified glass ionomer cement Vitremer in double-distilled water $(p<0.05)$. All materials released significantly more fluoride in double-distilled water than in artificial saliva $(p<0.05)$. In artificial saliva, none of the materials were observed to release aluminum. Conclusion: It was concluded that storage media and method of analysis should be taken into account when the fluoride and aluminum release from dental materials is assessed.
\end{abstract}

Key words: Aluminum. Fluorides. Chromatography.

\section{INTRODUCTION}

Fluoride released from restorative materials can inhibit demineralization as well as bacterial activities such as colonization and acid production ${ }^{29}$. The most important of these fluoride-releasing restorative materials are conventional glass ionomer cement (GIC), resin-modified glass ionomer cement (RMGIC) and polyacid-modified composite resin (PMCR). Fluoride-releasing composites are also available. Both PMCRs and fluoride-releasing composites are known to release lower levels of fluoride than conventional $\mathrm{GICs}^{3,26}$.

In addition to fluoride, GICs have been found to release aluminum into an ambient solution after setting ${ }^{21}$. The antibacterial activity of aluminum salt solutions against cariogenic micro-organisms has been previously reported ${ }^{23}$. Considering that the inhibition of Streptococcus mutans ATPase is higher when $\mathrm{F}$ and $\mathrm{Al}$ are combined ${ }^{16,17}$, the simultaneous release of aluminum and fluoride from dental material may play an important role in caries prevention ${ }^{17}$.

Fluoride ion-selective electrodes (ISE) and ion chromatography (IC) are the traditional techniques used to measure fluoride release ${ }^{19}$. Although ISE represents a simple and convenient method for measuring fluoride release, it is difficult to distinguish between free fluoride ions and fluoride complexes released from materials, both of which are detected by ISE ${ }^{6,30}$. In contrast, IC does not measure fluoride complexes and is able to detect low concentrations of fluoride ions that may not be detected by ISE $^{19}$. This distinction is important because only free fluoride ions can enhance tooth resistance to secondary caries attacks around restorations ${ }^{13}$.

Although numerous studies have examined fluoride release from restorative materials ${ }^{2,3,11,19,26}$, little research has been conducted on aluminum 
release or the association between fluoride and aluminum release $e^{7,16,21,25}$. This study aimed at measuring the release of fluoride and aluminum from different dental materials using IC.

\section{MATERIAL AND METHODS}

\section{Test specimens}

Details of the restorative materials evaluated are provided in Figure 1. For each material, 20 disc-shaped specimens were prepared in polytetrafluoroethylene molds (10 mm in diameter and $1 \mathrm{~mm}$ depth) according to the manufacturers' instructions. A nylon thread was incorporated into each specimen so that it could be suspended in a solution, and excess material was removed by placing the filled mold between 2 glass slides, each covered with a transparent Mylar strip (Henry Schein, Melville, NY, USA), and gently pressing them together. The conventional GIC specimens were allowed to set under pressure at room temperature for $10 \mathrm{~min}$. All other specimens were light-polymerized for $40 \mathrm{~s}$ using a visible light-curing unit (Hilux Dental Curing, Benlioglu Dental Inc, Ankara, Turkey). Specimens were removed from their molds, wet-ground with 500-1200-grit silicon carbide paper and placed in a $37^{\circ} \mathrm{C} \pm 2^{\circ} \mathrm{C}$ oven for $24 \mathrm{~h}$ to ensure a complete set.

\section{Fluoride and aluminum release}

Ten specimens of each material were immersed in $5 \mathrm{~mL}$ artificial saliva prepared according to Hayacibara, et al. ${ }^{17}$ (2003), and the remaining 10 specimens of each material were immersed in $5 \mathrm{~mL}$ double-distilled water. Solutions were changed daily during the first week. Discs were removed from the solutions, rinsed with double-distilled water, dried with absorbent paper and transferred to new tubes containing $5 \mathrm{~mL}$ of fresh solutions. Fluoride/ aluminum concentrations were measured using IC, with measurements taken daily during the first week (days 1-7) and once a week thereafter (days 14 and 21) to determine cumulative concentrations.

\section{Statistical analysis}

Statistical analysis of fluoride and aluminum release was performed using two-way ANOVA and Duncan's multiple range tests $(p<0.05)$. Pearson's correlation analysis was undertaken between fluoride and aluminum release in each medium.

\section{RESULTS}

Mean $( \pm S D)$ amounts of fluoride ions released from each material in double-distilled water and artificial saliva are shown in Figures 2 and 3.

Both Kavitan Plus (SpofaDental, Jičín, Czech Republic) and Vitremer (3M ESPE, St.Paul, MN, USA) exhibited an initial fluoride "burst effect" that was not observed with Dyract Extra (Dentsply DeTrey GmbH, Konstanz, Germany) or Surefil (Dentsply DeTrey GmbH).

The amount of fluoride released on day 1 in both artificial saliva and double-distilled water

\begin{tabular}{|c|c|c|}
\hline Material & Type & Manufacturer \\
\hline Kavitan Plus & Conventional glass ionomer cement & SpofaDental, Czech Republic \\
\hline Vitremer & Resin modified glass ionomer cement & 3M ESPE, St.Paul, MN, USA \\
\hline Dyract Extra & Polyacid modified glass ionomer cement & Dentsply, DeTrey GmbH, Konstanz, Germany \\
\hline Surefil & Fluoride-releasing composite resin & Dentsply, DeTrey GmbH, Konstanz, Germany \\
\hline
\end{tabular}

Figure 1- Restorative materials selected for this investigation and their manufacturers

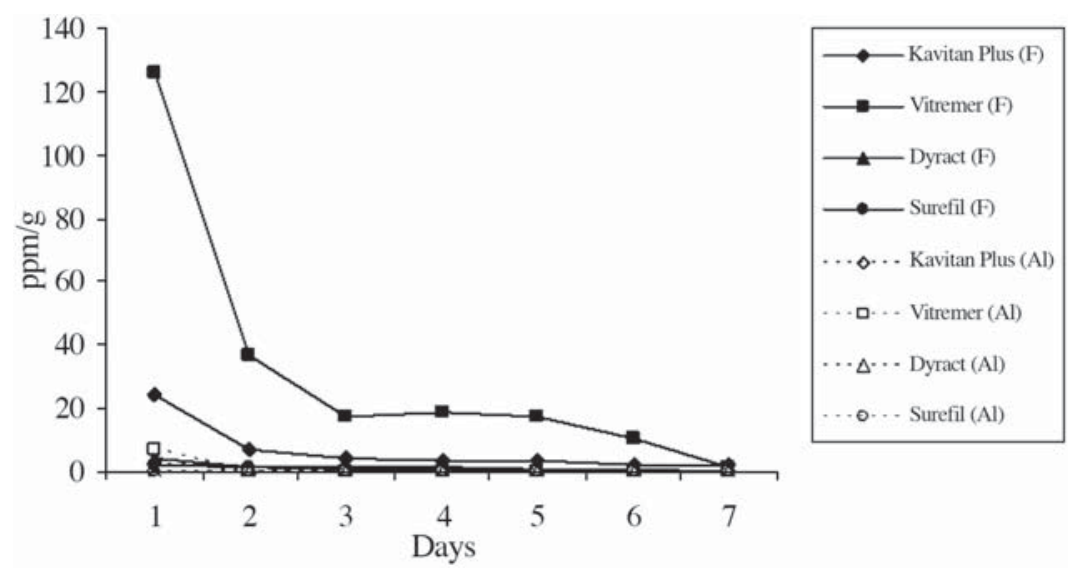

Figure 2- Fluoride and aluminum released from each materials in double distilled water during the first 7 days 

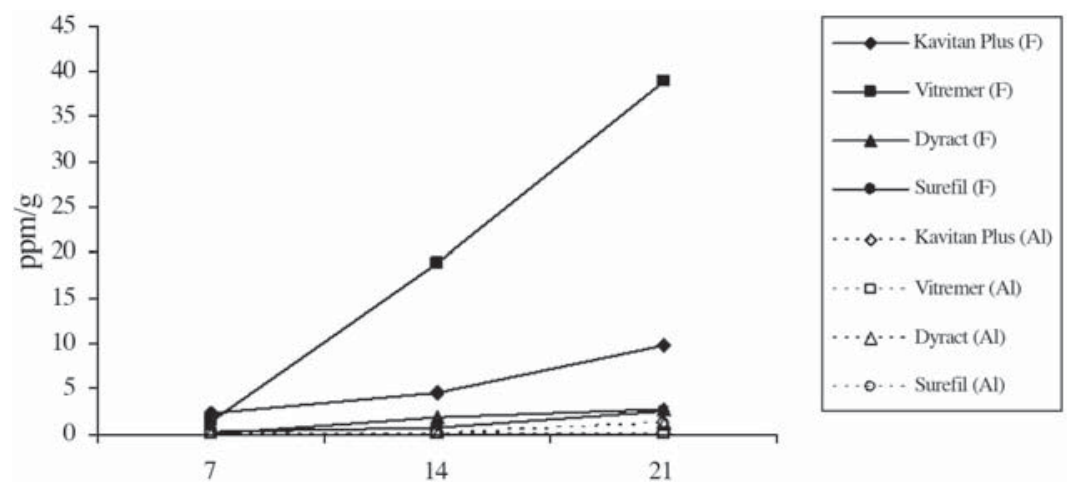

Figure 3- Cumulative fluoride and aluminum released from each material in double distilled water after day 7

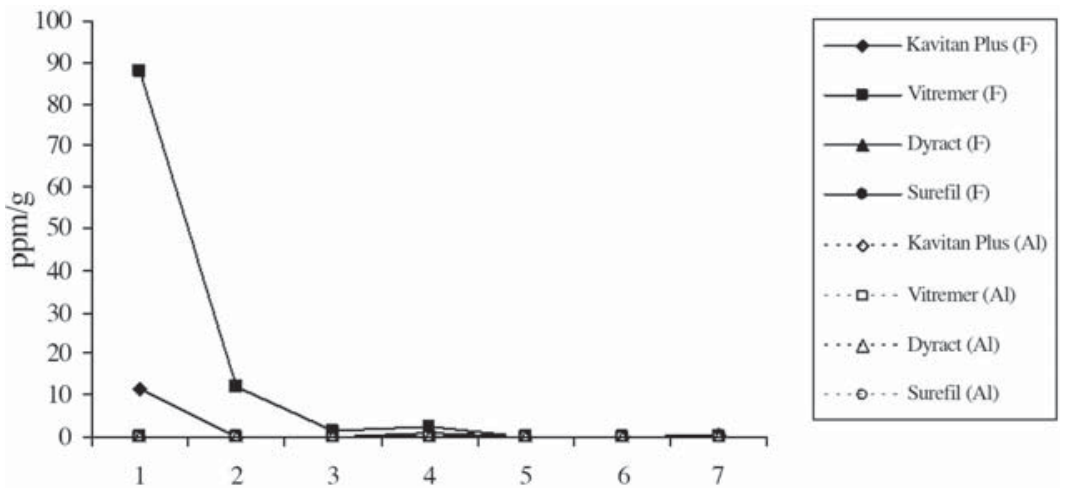

Figure 4- Fluoride and aluminum released from each material in artificial saliva during the first 7 days
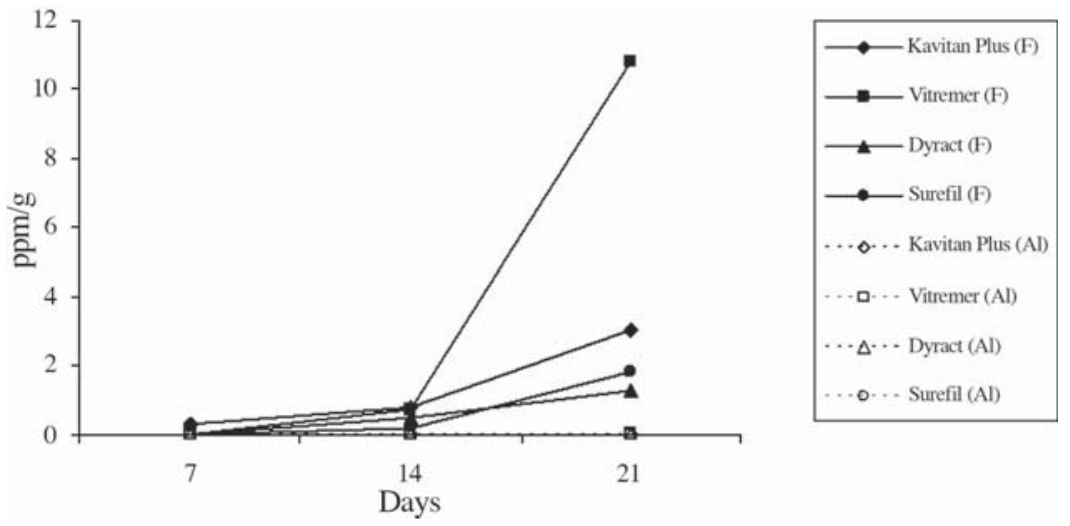

Figure 5- Cumulative fluoride and aluminum released from each material in artificial saliva after day 7

differed significantly among all materials except for Dyract and Surefil $(p<0.05)$. In double-distilled water, after immersion for $24 \mathrm{~h}$ (day 1 ), Vitremer released the highest amount of fluoride, followed by Kavitan Plus, Dyract Extra and Surefil (Figure 2). In artificial saliva, Vitremer also tended to have the highest fluoride release at all times, and no fluoride release was detected from either Dyract Extra or Surefil until day 14.

Vitremer also released the highest amount of aluminum in double-distilled water on day 1 , followed by Kavitan Plus, whereas no aluminum release was detected for Dyract Extra or Surefil. With the exception of day 1 , the levels of aluminum released from all materials in double-distilled water and artificial saliva were below the limits of detection throughout the 21-day test period (Figure 2-5).

The mean fluoride release was significantly higher in double-distilled water than in artificial saliva for all materials $(p<0.05)$.

No correlation was found between the amounts of fluoride and aluminum released in either doubledistilled water or artificial saliva.

\section{DISCUSSION}

It is generally agreed that fluoride facilitates remineralization and prevents demineralization ${ }^{28,29}$. The fluoride-releasing ability of GICs has been 
shown to offer resistance to secondary caries formation around restorations ${ }^{27}$ as a result of fluoride penetration into mineralized dentin ${ }^{22}$.

Previous studies have shown GIC and RMGIC to release more fluoride than PMCR and composite resin $^{3,26}$. GIC have been shown to release the highest amounts of fluoride during the first day of application in a phenomenon known as the "burst effect" ${ }^{\prime 3}$. This initial burst of fluoride has been found to reduce the viability of any bacteria remaining in inner carious dentin and to promote enamel/dentin remineralization ${ }^{10}$.

In this study, the conventional GIC Kavitan Plus and the RMGIC Vitremer were observed to produce a "burst effect", whereas the PMCR Dyract Extra and the fluoride-containing composite resin Surefil produced no initial burst of fluoride and showed lower constant fluoride release than Kavitan Plus and Vitremer. The "burst effect" demonstrated by Kavitan Plus and Vitremer may be due to the moisture sensitivity of GIC during the maturation period. The rapid fall of fluoride release during subsequent days is likely to be the result of the initial burst of fluoride released from the glass particles as they dissolve in the polyalkenoate acid during the setting reaction ${ }^{4}$. The latter slow release occurs as the glass dissolves in the acidified water of the hydrogel matrix ${ }^{8}$.

Previous studies have reported fluoride release from RMGIC to be higher than or the same as conventional $\mathrm{GIC}^{2,11,27}$. Among the materials tested in the present study, Vitremer released the highest amount of fluoride. The larger pore size and greater porosity of RMGIC in comparison to GIC may explain the difference in the initial leaching of fluoride from the glass particles ${ }^{18}$, and the type and amount of resin used in photochemical polymerization may also affect fluoride release rates ${ }^{20}$.

PMCRs, which are formed by adding acidic polymer to a methacrylate resin matrix ${ }^{2}$, are meant to combine the positive characteristics of GICs and composites; however, studies have shown PMCRs actually produce few responses typical of glass ionomers ${ }^{15,26}$. In the present study, the fluoriderelease values of the PMCR Dyract were lower than those of the GIC and RMCIG tested, indicating that the release of fluoride did not increase as a result of the addition of polyacids to resin ${ }^{1}$.

Amounts of fluoride released from composite resin tend to be far lower than the amounts released from conventional or resin-modified GIC and somewhat lower than the amount release from PMCR. In the present study, the fluoride-containing composite resin Surefil had the lowest levels of fluoride release. This finding is in agreement with Attar and Onen ${ }^{3}$ (2002) and suggests that the incorporation of fluoride compounds into resin composition does not improve fluoride release.
Historically, most in vitro fluoride-release studies have been performed using a static immersion medium, most commonly distilled or deionized water or artificial saliva ${ }^{12}$. The amount of fluoride released from dental materials has been shown to vary considerably according to the type of storage medium used 5,9 . The present study also found that the immersion medium may have considerable influence on the release of fluoride from dental materials. All four materials tested in this study released higher amounts of fluoride into doubledistilled water than into artificial saliva, indicating that fluoride release is significantly influenced by the ionic strength and composition of artificial saliva.

In addition to fluoride, some dental materials also release aluminum, another substance with anticariogenic properties that can enhance the effect of fluoride ${ }^{17}$. Aluminum forms complexes with fluoride that result in reduced levels of free fluoride ${ }^{14}$. The highest amounts of aluminum are released during the first $24 \mathrm{~h}$ after setting ${ }^{24}$. The amount of aluminum released decreases with the maturation of the glass ionomer cement, as the aluminum ions close to the surface are washed out of the cement and those that remain are trapped deep within the matrix ${ }^{21}$. In the present study, the only observable aluminum release was from the conventional and resin-modified GICs during the first day in double-distilled water. The RMGIC Vitremer released a higher amount of aluminum than the conventional GIC Kavitan Plus. No aluminum release was observed from any of the restorative materials tested when artificial saliva was used as the storage medium. This finding is supported by the fact that the release of aluminum from materials in artificial saliva is very low and was not detected.

\section{CONCLUSION}

As a general rule, a restorative material with a high level of fluoride release is appropriate for treating children with a high rate of caries and in other situations where optimal fluoride release is a high priority, whereas other restorative materials can be used when fluoride release is of lesser importance. The results of this study show that the levels of aluminum and fluoride released from restorative materials vary according to the type of restorative material. RMGIC was found to have the highest levels of fluoride and aluminum release. In view of this finding, from a clinical standpoint, caries restoration with RMGIC may play a significant role in the prevention of secondary caries in cariesactive children. In addition, studies that assess the anticariogenic potential of dental restorative materials by measuring the amounts of fluoride and 
aluminum released should take into account the effects of storage media on release levels.

\section{ACKNOWLEDGEMENTS}

This research was funded by Turkiye Bilimsel ve Teknolojik Arastirma Kurumu, Türkiye, [\#105S382 (SBAG-3189)].

\section{REFERENCES}

1- Aboush YE, Torabzadeh H. Fluoride release from tooth-colored restorative materials: a 12-month report. J Can Dent Assoc. 1998;64:561-4,568.

2- Araujo FB, García-Godoy F, Cury JA, Conceição EN. Fluoride release from fluoride-containing materials. Oper Dent. 1996;21:185-90.

3- Attar N, Onen A. Fluoride release and uptake characteristics of aesthetic restorative materials. J Oral Rehabil. 2002;29:791-8.

4- Attar N, Turgut MD. Fluoride release and uptake capacities of fluoride-releasing restorative materials. Oper Dent. 2003;28:395402.

5- Carvalho AS, Cury JA. Fluoride release from some dental materials in different solutions. Oper Dent. 1999;24:14-9.

6- Czarnecka B, Limanowska-Shaw H, Nicholson JW. Buffering and ion-release by a glass-ionomer cement under near-neutral and acidic conditions. Biomaterials. 2002;23:2783-8.

7- Czarnecka B, Nicholson JW. Ion release by resin-modified glass-ionomer cements into water and lactic acid solutions. J Dent. 2006;34:539-43.

8- De Moor RJ, Verbeeck RM, De Maeyer EA. Fluoride release profiles of restorative glass ionomer formulations. Dent Mater. $1996 ; 12: 88-95$.

9- El Mallakh BF, Sarkar NK. Fluoride release from glass-ionomer cements in de-ionized water and artificial saliva. Dent Mater. 1990;6:118-22.

10- Forsten L. Fluoride release and uptake by glass-ionomers and related materials and its clinical effect. Biomaterials. 1998;19:503-8.

11- Forsten L. Resin-modified glass ionomer cements: fluoride release and uptake. Acta Odontol Scand. 1995;53:222-5.

12- Freedman R, Diefenderfer KE. Effects of daily fluoride exposures on fluoride release by glass ionomer-based restoratives. Oper Dent. 2003;28:178-85.

13- Gedalia I, Mayer I, Giron J, Deutsch D. Fluoride deposition in the bones of rats determined by fluoride and X-ray diffraction analysis. Arch Oral Biol. 1982;27:823-5.
14- Gjorgievska E, Nicholson JW, Gjorgovski I, Iljovska S. Aluminium and fluoride release into artificial saliva from dental restoratives placed in teeth. J Mater Sci Mater Med. 2008;19:31637.

15- Guggenberger R, May R, Stefan KP. New trends in glassionomer chemistry. Biomaterials. 1998;19:479-83.

16- Hayacibara MF, Ambrozano GM, Cury JA. Simultaneous release of fluoride and aluminium from dental materials in various immersion media. Oper Dent. 2004;29:16-22.

17- Hayacibara MF, Rosa OP, Koo H, Torres SA, Costa B, Cury JA. Effects of fluoride and aluminum from ionomeric materials on $\mathrm{S}$. mutans biofilm. J Dent Res. 2003;82:267-71.

18- Hsu HM, Huang GF, Chang HH, Wang YL, Guo MK. A continuous flow system for assessing fluoride release/uptake of fluoridecontaining restorative materials. Dent Mater. 2004;20:740-9. 19- Itota T, Carrick TE, Rusby S, Al-Naimi OT, Yoshiyama M, McCabe JF. Determination of fluoride ions released from resinbased dental materials using ion-selective electrode and ion chromatograph. J Dent. 2004;32:117-22.

20- Momoi Y, McCabe JF. Fluoride release from light-activated glass ionomer restorative cements. Dent Mater. 1993;9:151-4. 21- Nakajima $\mathrm{H}$, Komatsu $\mathrm{H}$, Okabe T. Aluminium ions in analysis of released fluoride from glass ionomers. J Dent. 1997;25:137-44. 22- Nakajima M, Okuda M, Ogata M, Pereira PN, Tagami J, Pashley $\mathrm{DH}$. The durability of a fluoride-releasing resin adhesive system to dentin. Oper Dent. 2003;28:186-92.

23- Oppermann RV, Rölla G. Effect of some polyvalent cations on the acidogenicity of dental plaque in vivo. Caries Res. $1980 ; 14: 422-7$.

24- Sales D, Sae-Lee D, Matsuya S, Ana ID. Short-term fluoride and cations release from polyacid-modified composites in a distilled water, and an acidic lactate buffer. Biomaterials. 2003;24:1687-96. 25- Savarino L, Cervellati M, Stea S, Cavedagna D, Donati ME, Pizzoferrato $A$, et al. In vitro investigation of aluminum and fluoride release from compomers, conventional and resin-modified glassionomer cements: a standardized approach. J Biomater Sci Polym Ed. 2000;11:289-300.

26- Suljak JP, Hatibovic-Kofman S. A fluoride release-adsorptionrelease system applied to fluoride-releasing restorative materials. Quintessence Int. 1996;27:635-8.

27- Tam LE, Chan GP, Yim D. In vitro caries inhibition effects by conventional and resin-modified glass-ionomer restorations. Oper Dent. 1997;22:4-14.

28- Ten Cate JM. Remineralization of caries lesions extending into dentin. J Dent Res. 2001;80:1407-11.

29- Ten Cate JM, van Duinen RN. Hypermineralization of dentinal lesions adjacent to glass-ionomer cement restorations. J Dent Res. 1995; 74:1266-71.

30- Williams JA, Billington RW, Pearson GJ. The glass ionomer cement: the sources of soluble fluoride. Biomaterials. 2002;23:2191-200. 